Bartın Üniversitesi İktisadi ve İdari Bilimler Fakültesi Dergisi, 2021, Cilt 12, Sayı 23

Bartın University Journal of Faculty of Economics and Administrative Sciences, 2021, Volume 12, Issue 23

E-ISSN: 2148-2497

http://iibfdergi.bartin.edu.tr/

https://dergipark.org.tr/tr/pub/bartiniibf

Araştırma Makalesi, Gönderim Tarihi: 19.03.2021; Kabul Tarihi: 22.05.2021

\title{
Kripto Para, Para mıdır Döngüsünde Kabul Edilebilirlik Üzerine Ampirik Bir Uygulama ${ }^{1}$
}

\author{
Doç. Dr. Murat ATÍK \\ Milli Savunma Üniversitesi Kara Harp Okulu İşletme Bölümü \\ matik@kho.edu.tr, Orcid ID: 0000-0002-5150-0203 \\ Doç. Dr. Yaşar KÖSE \\ Türk Hava Kurumu Üniversitesi İşletme Fakültesi \\ ykose@thk.edu.tr, Orcid ID: 0000-0003-0073-2095

\section{Dr. Öğ. Üyesi Bülent YILMAZ} \\ Milli Savunma Üniversitesi Kara Harp Okulu İşletme Bölümü \\ byilmaz@kho.edu.tr, Orcid ID: 0000-0003-1114-2365
}

\section{Öz}

Kripto Paralar, hayatımızın tüm süreçlerinde kullandığımız diğer para birimleri gibi günümüzde kullanılmaya başlanmıştır. Uluslararası piyasalarda kripto paraların kullanılması ile birlikte ulusal para birimlerinin değerlerinin belirlendiği gibi bir kontrol mekanizmasının olmaması ve hukuki altyapı eksikliği en büyük handikaplar olarak karşımıza çıkmaktadır. Ortaya çıkan bu olumsuzlukların yanı sıra belki de piyasaları endişelendiren en önemli husus kripto para birimlerinin gerçek para birimleri gibi kullanılıp kullanılmayacağıdır. Söz konusu kripto para birimlerinin takibi de gerçek para birimleri gibi ulusal ve yasal düzenlemeler ve düzenleyiciler tarafindan değil şifrelenmiş bir veri tabanı olarak isimlendirilen Blockchain teknolojisi sayesinde yapılabilmektedir. Çalışmanın amacı, Blockchain teknolojisi açıklayarak, bir uygulama yardımıyla kripto para birimlerinin paranın temel fonksiyonlarını sağlayıp sağlayamadığını belirlemektir. Bu aşamada, analiz edilen zaman dilimlerinde birinci ve ikinci nesil birim kök testleri kullanılarak beş farklı kripto para birimi değerlendirilmiş ve kripto para birimlerinin normal para birimleri gibi bir tasarruf aracı ve hesap birimi olma işlevlerini yerine getirip getiremeyeceği incelenmiştir. Birinci ve ikinci nesil birim kök testlerinin bulguları, kripto para birimlerinin tasarruf aracı ve hesap birimi olma işlevlerini yerine getiremeyeceklerini göstermektedir.

Anahtar Kelimeler: Kripto para, Blockchain Teknolojisi, Para Fonksiyonları, Kriptografi, Bitcoin.

Jel Sinıflandırması: E 41, E 42, E 51, F 31

\footnotetext{
${ }^{1} \mathrm{Bu}$ çalışma 23. Finans Sempozyumunda bildiri olarak sunulmuştur.

APA: Atik, M., Köse, Y. \& Yılmaz, B. (2021). Kripto Para, Para mıdır Döngüsünde Kabul Edilebilirlik Üzerine Ampirik Bir Uygulama. Bartın Üniversitesi İktisadi ve İdari Bilimler Fakültesi Dergisi, 12 (23), 155 172.

APA: Atik, M., Köse, Y. \& Yılmaz, B. (2021). An Empirical Analysis About The Acceptability of The Crypto Currencies As Money. Bartın Unıversity Journal of Faculty of Economics and Administratıve Sciences, 12 (23), 155-172.
} 


\title{
An Empirical Analysis About The Acceptability of The Crypto Currencies As Money
}

\begin{abstract}
Crypto Money has started to be used today, like other currencies we use in all processes of our lives. With the use of cryptocurrencies in international markets, the lack of a control mechanism that determines the values of national currencies and the lack of legal infrastructure are the biggest handicaps. In addition to these negativities, perhaps the most important issue that worries the markets is whether crypto currencies will be used as real currencies. The tracking of these cryptocurrencies can also be done by Blockchain technology, which is called an encrypted database, not by national and legal regulations and regulators like real currencies. The aim of the study is to explain Blockchain technology and determine whether cryptocurrencies can provide the basic functions of money with the help of an application. At this stage, five different crypto currencies were evaluated using first and second generation unit root tests in the analyzed time frames and it was examined whether crypto currencies could fulfill the functions of being a savings tool and unit of account like normal currencies. The findings of the first and second generation unit root tests show that cryptocurrencies cannot fulfill their functions as a savings tool and unit of account.
\end{abstract}

Keywords: Crypto Currency, Blockchain Technology, Functions of Money, Cryptography, Bitcoin.

Jel Classification: E 41, E 42, E 51, F 31

\section{Giriş}

Blockchain teknolojisi, kriptografi olarak adlandırılan özel şifreleme metodu ile sürekli büyüyen veri yapısı oluşturan ve doğrulamak için belirli bazı matematiksel algoritmalar kullanan bir mekanizmadır. Blokchain, dağıtık bir defter işlevi (Distrubuted Ledger) gören “işlem blokları” zinciridir. Dağıtılmış defter, birden çok site, kurum veya coğrafyadaki ağ üzerinden yayılmış ve senkronize bir veri tabanıdır. Dağıtılmış defterler işlemlerin halka açık tanıklara sahip olmasını sağlayarak herhangi bir siber saldırıyı zor hale getirmektedir. Banka ve finans kurumları dağıtık defter teknolojisini kullanarak güvenliğin yanı sıra maliyeti düşürmeyi ve işlem prosedürlerini bu teknoloji ile azaltmayı amaçlamaktadır (Demirdöğen, 2019: 311-312).

Ağın her bir düğümündeki (node) katılımcılar, söz konusu ağda paylaşılan kayıtlara erişebilmekte ve aynı kopyanın sahibi olmaktadır. Bunun yanı sıra defterlerde yapılan tüm değişiklikler veya ilaveler, katılımcıların tamamına çok kısa zaman dilimleri içerisinde yansıtılmakta ve kopyalanmaktadır. Dağıtılmış defter teknolojisinin altında yatan, Bitcoin ile aynı teknoloji olan Blockchain tekonolojisidir. Blockchain, dağıtık bir veri tabanına benzetilmektedir (Avunduk ve Aşan, 2018: 374; Lemieux, 2016:110-113). 
Veri tabanına yapılan eklentiler, her türlü bilgiyi içeren yeni bir "veri bloğu" yaratan üyeler (ağ düğümleri) tarafından başlatılmaktadır. Bu yeni blok ağdaki her noda şifreli bir şekilde kriptografi kullanarak yayınlanmakta ve işlem ayrıntıları açıklanmamaktadır. Genel olarak "fikir birliği mekanizması" olarak adlandırılan önceden tanımlanmış bir algoritmik doğrulama yöntemi ile doğrulanarak yeni blok, blok zincirine eklenmekte ve ağda dağıtılan işlem defterinde güncellenmektedir. Blockchain teknolojisinin işleyiş mekanizması Şekil 1'de gösterilmiştir.

\section{Şekil 1: Blokchain Çalışma Şekli}

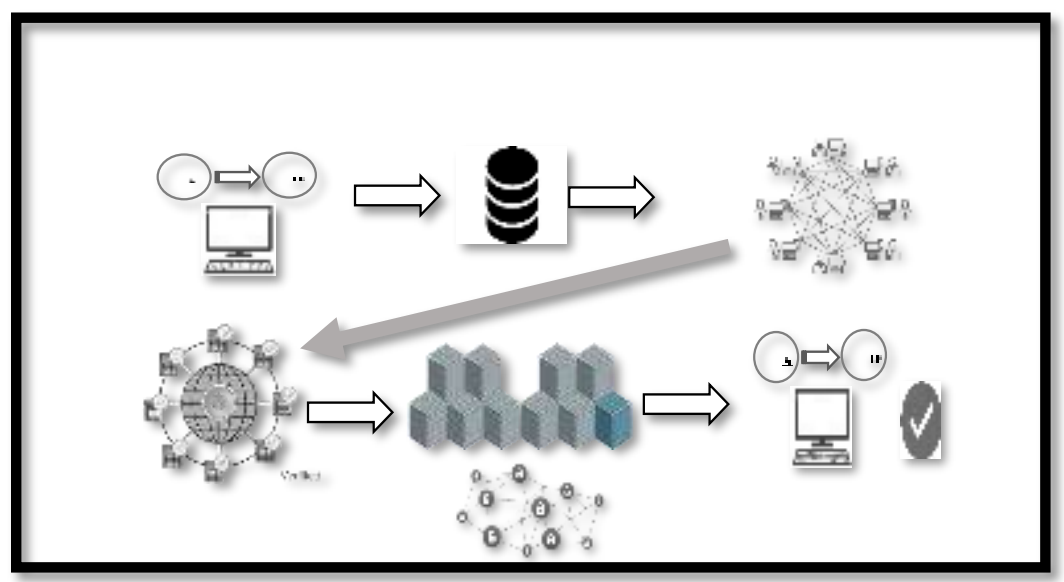

Kaynak: (Houben ve Snyers, 2018:17).

Avrupa Merkez Bankası Kripto parayı, sanal paranın bir alt başlığı içinde sınıflamıştır. $\mathrm{Bu}$ açıdan incelendiğinde üç tip sanal para vardır: Bunlar; (1) Kapalı sistem içerisinde ve on-line oyunlarda kullanılan sanal paralar, (2) Tek taraflı olarak reel ekonomiye bağlı sanal para birimleri (Bir dönüşüm oranı ile para birimini, sanal mal ve hizmetleri satın almak veya istisnai olarak gerçek mal ve hizmetleri satın almak için kullanılabilmektedir. Örneğin Facebook kredileri) ve (3) İki taraflı reel ekonomiyle bağlantılı sanal para birimleri (Hem sanal parayı satın almak hem de bu para birimlerini satmak için dönüşüm oranları bulunmaktadır. Satın alınan para birimi hem sanal malları hem de hizmetleri olarak satın almak için kullanılabilmektedir). Bitcoin gibi kripto paralar sanal para statüsünde olup hem geleneksel paralar gibi ticaret hayatında hem de sanal ortamda gerçek mal-hizmet satın alımlarında kullanılabilmektedir (Houben ve Snyers, 2018:21).

Kripto para piyasasında yer alan farklı aktörler belirli fonksiyonları yerine getirmektedir. Bunlardan kripto para kullanıcıları, kripto paraya sahip olan ve bunları gerçek veya sanal mal ve hizmetleri satın almada kullanan özel veya tüzel kişilerdir. Madenciler ise, "kriptografik bir bulmaca"yı çözerek blok zincirindeki işlemlerin onaylanmasına katılan aktörler olarak görülmektedir. Madenciler, bilgi işlem bilgileri 
aracılığıyla ağa destek vererek karşılığında kripto para alan gruptur. Üçüncü aktör, kripto para birimi değişimini gerçekleştiren kişiler, kurumlar veya platformlardır. Bunlar genellikle belirli bir ücretin ödenmesine karşılık (yani bir komisyon) takas hizmeti sunan kişi veya kurumlardan oluşmaktadır. Genellikle hem bir borsa, hem de döviz bürosu olarak işlev görmektedir. Örnek olarak, Bitfinex, HitBTC, Kraken, CoinbaseGDAX birer değişim platformlarıdır. Dördüncü aktör cüzdan sağlayıcılardır. Cüzdan sağlayıcılar; paraları elde tutmak, saklamak ve aktarmak için kripto para birimi kullanıcılarına dijital cüzdan veya e-cüzdan sağlayan işletmelerdir. Bir cüzdan sağlayıcı genellikle bir şifreli para birimi kullanıcısının işlem geçmişini, normal bir banka hesabına benzeyen kolay okunabilir bir formata çevirmektedir. Beşinci aktör kripto para şirketini kuran ve başlangıçtaki kuralları koyan yatırımcılardır. Son aktör grubu ise kripto parayı arz edenlerdir. Bunlar başlangıçta belirli bir karşılık üzerinden veya karşılıksız olarak kripto para arzında bulunmaktadır. Kripto paraları arz edenler, kripto para şirket yatırımcıları ile aynı kişiler veya kuruluşlar olabilmektedir.

Geçtiğimiz birkaç yıl boyunca istikrarlı bir büyüme yaşadıktan sonra, kripto para birimleri piyasası 2019 Mayıs rakamlarıyla; 185.173.260.589 \$’lık piyasa değerine ulaşmışlardır. Kripto para piyasasında 2.160 farklı kripto para bulunmakta ve günlük ortalama işlem hacimleri 50 Milyar \$ seviyelerine kadar ulaşabilmektedir. Bu piyasaların \%50-55'de Bitcoinle işlem yapılmaktadır (https://coinmarketcap.com/. e.t .08.05.2019). En yaygın olarak kullanılan Bitcoin'e alternatif olarak çıkarılan Altcoin ve Altcoin'in bünyesinde bulunan, Ethereum, Ripple, Bitcoin Cash, Litecoin, EOS, Binance Coin, Tether, Stellar, Cardano, TRON, Monero, Dash gibi burada daha ismi sayılmayan ancak yapılan analizde kapsama alınan yüzlerce kripto paraların birçoğu günlük işlemlerine devam etmektedir.

\section{Paranın Fonksiyonları}

Kripto paranın para olarak kabul edilip edilemeyeceğini belirleyebilmek için ilk olarak paranın fonksiyonları incelenmelidir. Herhangi bir nesnenin para olarak kabul edilebilmesi, ekonomide temel olarak üç fonksiyonun yerine getirilmesine bağlıdır. Paranın; değişim aracı olma, hesap birimi olma ve değer saklama fonksiyonu olma özellikleri temel üç fonksiyonudur (Mishkin, 2016: 96-98). Diğer bir bakış açısıyla da para yukarıda belirtilen üç fonksiyona ilave ertelenmiş bir ödeme standard1 fonksiyonuna da sahip olmalıdır (Hubbard ve O'Brien, 2014: 28). Keynes, paranın fonksiyonlarıa göre bireyler ve işletmeler sırasıyla işlem (transactions), ihtiyat (precutionary) ve spekülasyon nedeni ile para bulundurduklarını belirtmektedir (Akt: Berk, 2011: 121). Keynes'in yaklaşımı paranın yukarıda belirtilen fonksiyonlarına uyarlandığında; işlem nedeni ve değişim aracı olma fonksiyonunu; ihtiyat ve spekülasyon nedenini ile de değer saklama fonksiyonunun benzer anlam taşıdığ değerlendirilmektedir.

Bir değişim aracı olarak para, hemen hemen tüm piyasa işlemlerinde alınan mal ve hizmetlerin karşılığında ödeme aracı amacıyla kullanılmaktadır. Barter (takas) 
yönteminde her bir mal ve hizmeti diğeri ile değiştirmek için harcanacak zaman doğal olarak oldukça fazla ve ekonomik olarak rasyonel olmamaktadır. Bu aşamada para, mal ve hizmet değişiminde kabul görmüş bir değişim aracı olarak toplum ve ekonomilerde harcanacak zamanı en aza indirerek ekonomik etkinliği artırmaktadır. Yine barter ekonomisiyle kıyaslanacak olursa, takas işlemlerindeki işlem maliyetleri oldukça yüksektir. Bu noktada da para bir değişim aracı olarak ekonomilerde işlem maliyetlerini en aza indirerek ekonomik anlamda uzmanlaşma ve işbölümüne katkı sağlamaktadır.

Bir hesap birimi olarak paranın fonksiyonu, mal ve hizmetlerin değerinin para ile ölçülmesinden kaynaklanmaktadır. Paranın fonksiyonu ayrıca çeşitli mal ve hizmetlerin değerinin standardize edilmiş biçimde ölçülmesi ve bunların birbirlerine göre nispi değerlerinin belirlenmesini sağlamaktadır. Paranın hesap birimi olması, işlem maliyetleri azaltarak çok karmaşık ekonomilerde bile kolaylıkla kullanımını sağlamaktadır.

Değer saklama fonksiyonu, bireylerin veya işletmelerin elde ettikleri gelirlerin tamamını veya bir kısmını elde edilen zamandan farklı bir zamanda harcamak istemesinden kaynaklanmaktadır. Gelirin kazanıldığı tarihten harcandığı tarihe kadar satın alma gücünü muhafaza etmesi şeklinde de tanımı yapılmaktadır (Mishkin, 2016: 98). Paranın değer saklama fonksiyonunu yerine getirmesi açısından para kavramı yerine söz konusu fonksiyonu getirebilecek farklı varlıklarda bulunmaktadır. Örneğin; ev, arsa, mücevher, tahvil, hisse senedi gibi varlıklar da servet veya değer saklamak için kullanılabilmektedir. Hatta bu varlıklar elde bulundurulduğu zaman dilimi içinde kişiye fayda sağlayabilmektedir. Ancak bu tür varlıkların değerini koruyup, hızlı bir biçimde başka bir değişim aracına çevrilebilme olasılığı yani likiditesi düşük kalabilmektedir. Para, varlıklar arasında likiditesi en yüksek olandır ve başka bir varlığa dönüştürülmesine gerek yoktur. Yukarıdaki varlık ve emtiaların paraya dönüştürülmesi için çeşitli işlem maliyetine katlanılmasını gerektirmektedir. Bu işlem maliyetlerinden kaçınmak için diğer varlıklar değer deposu olarak daha büyük bir getiri beklentisi içinde olsalar da insanlar para tutmaya daha istekli olabilmektedir. Para, en likit varlık olsa da özellikle ülkelerde yaşanan yüksek enflasyon sonucunda satın alma gücündeki düşüşler para tutmanın cazibesini azaltmaktadır. Para ancak satın alma gücünü koruduğu sürece elde tutmada çekici olabilmektedir.

\section{Literatür İncelemesi}

Kripto paranın oluşturulması, gelişimi, kullanımı, yasal mevzuatı, avantajı ve dezavantajlarıyla ilgili olarak yazında çok sayıda çalışmalar yapılmış ve halen bu konu üzerinde çalışmalar yapılmaya devam etmektedir. Durque (2020), kripto para birimleri ve bunların altında yatan teknolojilerin araştırma ve geliştirilmesinde devletlerin oynadığı rolünü incelemiş, Çin gibi ülkelerin dünyada Amerikan Dolarının hükümranlığına karşılık olarak bu yeni dijital para türünün devlet destekli kripto para birimi olarak piyasaya sürmek ve dünya parasına dönüştürmek çabası içinde olduğunu belirlemiştir (Durque, 2020: 65). 
Malherbe vd. yaptı̆̆ı çalışmada, Bitcoin'in deflasyonist ve işlevsiz bir para rejiminin yanı sıra yüksek işlem maliyetlerine neden olabileceği için günlük para olarak kullanılamayacağı, diğer bazı kripto para birimlerinin yeni egemenlik biçimlerini oluşturacağı ve eğer sabit bir parasal arza dayalı olmasını sağlayacak şekilde merkez bankalarınca desteklenmesi durumunda parasal rejimde ilginç dönüşümlere yol açılabileceğini ifade etmişlerdir (Malherbe ve diğ., 2019: 127).

Grobys ve Sapkota 146 kripto para birimi hakkında 2014-2018 yılları arasında yaptığ 1 çalışmada kripto para birimlerinin yaklaşık \%60'ının temerrüde düştüğünü, oluşturdukları diskriminant modeliyle 1 aylık portföylerde alım ve satımlar sonucunda kripto para iflaslarının \%87'sini açıklayabildiklerini ve kripto para birimlerine yatırım yapmaktan kaçınmak isteyen yatırımcılar için oluşturdukları bu modelin bir tarama aracı olarak hizmet edebileceklerini bulmuşlardır (Grobys ve Sapkota, 2020: 5060).

Nishibe yaptığı çalışmada, kripto para birimleri de dahil olmak üzere modern paranın çeşitliliği ve evrimini tartışarak, Gresham yasasının "Kötü para iyiyi kovar" yaklaşımı doğrultusunda kripto para birimleri için, iyi para arayışında olan para kullanıcılarının para seçimini test etmiş ve kripto paranın istikrar kriterlerini geçemediğini tespit etmiştir (Nishibe, 2020: 1).

Fantacci yaptığı çalışmada Friedrich August Von Hayek'in önerdiği “Avrupa Ekonomik Topluluğu tarafından tartışılan tek para birimine uygulanabilir bir alternatif olarak para birimi rekabeti önerisi kapsamında; üye devletler arasında paranın serbest dolaşımının ve tüm döviz kontrollerinin kaldırılmasının, topluluk genelindeki vatandaşların herhangi bir üye devletin para birimini serbestçe kullanmalarına izin verilmesi koşuluyla, ulusal hükümetler tarafından verilen para birimleri arasında kolayca bir rekabete yol açabileceğì" öngörüsünden hareketle Hayek tarafindan Bitcoin'in öngörülen istikrarlı para ilkelerini gerçekten ne ölçüde somutlaştırdığı ve kripto para birimlerinin çoğalmasının bir parasal rekabet oluşturup oluşturmadığ araştırılmış ve algoritmalar tarafından yönetilen paraların var olduğu piyasalarda erdemli bir rekabetin olmayacağını ve bu anlamda kripto paranın desteklenemeyeceğini ifade etmiştir (Fantacci, 2019: 105-126).

Butler, 2018 yılında FED Başkanın kripto para birimlerinin kara para aklama için harika bir araç olduğunu beyan etmesi, buna paralel olarak birçok medyada atılan başlıkların bu gibi yorumları takip etmesi ve kripto para birimlerinin korkulması gereken önemli bir suç aracı olduğunu öne sürmeleri üzerine yapılan çalışmada popüler düşüncenin aksine, kripto para birimlerinin çok küçük bir suç yüzdesinde kullanıldığını ve birçok kişi için iddia edildiği gibi gelecekte büyük bir tehdit oluşturmadığını göstermiştir (Butler, 2019: 326).

Çarkacıoğlu (2016), Bitcoin'in ile itibari parayı mukayese ederek, Bitcoin gibi kripto paraların mali sistem ve işlem yapma açısından itibari paradan farklarını; aracısız işlem, merkezi olmama, değer taşıma fonksiyonu, düzenleme yetkisi, geriye dönük 
işlem durumu ve güvenlik gibi unsurlarla değerlendirerek kripto paralarda herhangi bir manipülasyonun yapılamayacağını ifade etmiştir.

Kaplanhan (2018) ise kripto paraları kriptoloji bilimini kullanarak matematiksel algoritmalarla şifrelenmiş dijital ve sanal bir para birimi olarak tanımlamakta ve kripto paraların kullanımındaki artışı ve değişim aracı olarak kullanılmaya başlamasındaki sebebini ise bir hükümet veya merkezi otoriteye bağlı olmamasına dayandırmaktadır.

Doğan (2020), para olarak görülmeye başlanan kripto paraların bilinme ve kullanım düzeyini tespit etmek amacıyla 400 üniversite öğrencisi ile yaptığı araştırmada üniversite öğrencilerinin kripto paralardan haberdar olduklarını ancak kripto paraları kullanım düzeylerinin düşük olduğunu tespit etmiştir. Bu durum kripto paraların henüz bir değişim aracı olma fonksiyonunu tam olarak yerine getiremediğinin bir göstergesi niteliğindedir.

Parlaktuna ve Güngül (2020), paranın değerli madenlere dayalı sistemlerden elektronik sistemlere geçişine kadarki süreçte ortak özelliğinin paranın somut bir varlık olmasını, bir varlığın para olarak tanımlanması için ekonomik açıdan geçerli 3 fonksiyonuna ilave yasal tanımının da mutlaka yapılması gerektiğini, kripto paraların ekonomik tanımındaki 3 fonksiyonu yerine getirmede hala zayıf kaldığını, değerini anlamak için mutlaka mevcut bilinen bir değerle tanımlamasının yapılması gerektiğini ifade edilmiştir. Ancak kripto paraların gelişim hızını da değerlendirerek kripto paraların paranın ikamesi olarak hangi düzeyde olduğunun belirlenmesinin ekonomik politikalar geliştirilmesi açısından önemli olduğunu vurgulamışlardır.

Lee vd. (2018), kripto paralar ile diğer geleneksel varlıklara yatırım riski ve getirisi arasındaki ilişkiyi incelemiş ve kripto para birimleri ile geleneksel varlıklar arasında getiri yönünden korelasyonun düşük olması sebebi ile portföye kripto paraların eklenmesinin getiri performansını arttırdığını tespit etmişlerdir. Bu durum kripto paraların bir yatırım fonksiyonu kimliğini kazanmaya başladığının bir göstergesi niteliğinde olduğu değerlendirilmektedir.

Bazı çalışmalarda ise kripto para sisteminin teorik olarak değiş tokuş ve değer saklama aracı gibi paranın tüm fonksiyonlarını taşıdığı ve merkez bankasına bağlı para birimleri ile aynı finansal araçlara sahip olduğu görüşü de hakimdir (Yıldırım, 2019: 269). Ancak bu görüşün tersine kripto paraları kontrol eden ve aracılık rolünü üstlenen bankacılık sistemi gibi bir kontrol unsurunun olmamasının kripto paralara olan güven unsurunu etkilediğini ifade eden çalışmalarda bulunmaktadır (Kesebir ve Günceler, 2019:607).

Kripto paralara ilişkin yasal zeminde de halen boşluklar vardır. Pirinççi (2018:51), kripto paraların para olarak görülebilmesindeki en büyük engellerden birisini sağlıklı bir hukuk zeminin olmamasını, hak ve yükümlülüklerin tanımlanmamasına bağlamaktadır. Ayrıca bu hukuki boşluğun birçok ülkede olduğunu da ifade etmektedir. 
Ülkelerin bu yeni para birimlerine adapte olamaması bazı ülkelerde yasaklanmalarına veya kullanımının sınırlandırılmasına sebep olmuştur (Şenbayram, 2019:89-90). Her ne kadar yasal zemindeki boşluklarda olsa ilginç bir şekilde kripto paraların gün geçtikçe kullanımı artış içerisindedir.

\section{Uygulama}

\subsection{Yöntem ve Varsayımlar}

Sermaye piyasalarındaki fiyat hareketlerinin rassal oluştuğu ve bu yüzden önceden fiyat tahmininin yapılamayacağı düşüncesi Etkin Piyasa Hipotezi ile ortaya çıkmıştır. Etkin piyasa hipotezi temel de rassal yürüyüş hipotezine (Random Walk Hypothesis) dayanmaktadır. Söz konusu hipoteze göre etkin olan sermaye piyasalarında hisse senedi fiyatları piyasada rassal bir hareket sergileyecekleri için fiyat hareketlerinin önceden tahmin edilmesi mümkün değildir. Gelecekteki hisse senedi fiyat tahmininin geçmişteki verilerin matematiksel araçlar veya grafikler gibi teknik analizlerle tahmininin yapılamayacağı ve kar edilemeyeceği ifade edilmiştir. Etkin piyasa hipotezine göre piyasada oluşan fiyat ile gelen bilgi arasında bir ilişki bulunmaktadır. Fiyat değişimi gelen yeni bilgilerin piyasa tarafından değerlendirilmesi ile oluşmaktadır. Piyasaların etkinliği piyasaların yeni gelen bilgilere ne kadar sürede tepki verdiğine bağlı olarak değişmektedir. Etkin piyasa hipotezine göre piyasalar; zayıf, yarı güçlü ve güçlü form olmak üzere üç ayrı şekilde gruplandırılmaktadır. Zayıf formda etkinlik, geçmiş fiyat hareketleri ile fiyat tahminin yapılamayacağı, yarı güçlü formda etkinlikte ise buna ek olarak halka açık diğer bilgilerin (muhasebe bilgileri, finansal tabloları, satın ve birleşme haberleri, temettü bilgileri, vb.) hisse fiyatlarını etkileyeceği ve son form olan güçlü formda etkinlikte de bütün bunlara ek firmaya ait içsel bilgilerin hisse senedi fiyatına etki edeceği görüşü bulunmaktadır.

Etkin piyasa hipotezine göre etkin bir piyasadan geçmiş fiyat hareketlerinden faydalanılarak geleceğe ilişkin tahminlerin yapılması mümkün değildir. Bu piyasalarda ortalamanın üstünde bir getirinin elde edilmesin mümkün değildir (Fama, 1965; Fama 1995). Etkin piyasa hipotezindeki bu varsayım altında kripto para piyasasının zayıf formda etkin olup olmadığı birinci ve ikinci nesil birim kök testleri kullanmak suretiyle tespit edilmiştir. Birim kök testleri sonucunda seçilen kripto paraların durağan olmadığ tespit edilir ise piyasanın zayıf formda etkin olmadığı ve geçmiş fiyat hareketleri ile ortalamanın üstünde bir getiri elde edilemeyecektir. Söz konusu bu durum ile kripto paraların paranın temel fonksiyonları sağlama konusu birleştirilerek kripto paraların para olup olmadığı konusunda genel bir değerlendirmede bulunulacaktır.

\subsection{Veri}

Analiz için beş kripto paranın piyasa ilk çıkışından itibaren oluşan kapanış fiyatları esas alınmıştır. 10 Haziran 2019 itibariyle Dünya üzerinde bulunan kripto para sayıs1 2.225 ve bu piyasaların büyüklüğ̈̈ 245.174.509.326\$'dır. Aynı tarihte kripto para piyasasında 24 saat içindeki günlük işlem hacmi ise 63.811.093.879\$ olarak 
gerçekleşmiştir. Tablo 1'de sunulan rakamlar kripto para piyasasının büyüklügüünü göstermesi açısından önemlidir.

Tablo 1: Beş Kripto Paraya Ait Piyasa Bilgileri

\begin{tabular}{|c|c|c|c|c|c|c|c|c|}
\hline $\begin{array}{l}\text { Kripto } \\
\text { Para }\end{array}$ & Sembol & $\begin{array}{c}\text { Pazar } \\
\text { Büyüklüğü (\$) }\end{array}$ & $\begin{array}{c}\text { Pazar } \\
\text { Payı (\%) }\end{array}$ & Dolaşımdaki Arz & İşlem (24h) (\$) & $\% 1 \mathrm{~h}$ & $\% 24 h$ & $\% 7 d$ \\
\hline Bitcoin & BTC & $\$ 136.592 .350 .657$ & 55,71 & 17.751 .062 & $\$ 17.837 .918 .347$ & $\begin{array}{c}- \\
0,65 \% \\
\end{array}$ & $\begin{array}{c}- \\
2,69 \% \\
\end{array}$ & $-9,86 \%$ \\
\hline Ethereum & ETH & $\$ 25.072 .903 .651$ & 10,23 & 106.430 .604 & $\$ 8.153 .050 .135$ & $\begin{array}{c}- \\
0,68 \% \\
\end{array}$ & $\begin{array}{c}- \\
3,53 \% \\
\end{array}$ & $\begin{array}{c}- \\
10,72 \% \\
\end{array}$ \\
\hline XRP & $\mathrm{XRP}$ & $\$ 16.389 .511 .014$ & 6,68 & 42.238 .947 .941 & $\$ 1.723 .719 .831$ & $\begin{array}{c}- \\
0,75 \% \\
\end{array}$ & $\begin{array}{c}- \\
5,59 \% \\
\end{array}$ & $\begin{array}{c}- \\
12,78 \% \\
\end{array}$ \\
\hline Litecoin & LTC & $\$ 7.196 .156 .454$ & 2,94 & 62.161 .626 & $\$ 4.460 .990 .136$ & $\begin{array}{c}- \\
0,99 \% \\
\end{array}$ & $\begin{array}{c}- \\
1,56 \% \\
\end{array}$ & $2,76 \%$ \\
\hline $\begin{array}{l}\text { Bitcoin } \\
\text { Cash } \\
\end{array}$ & $\mathrm{BCH}$ & $\$ 6.753 .564 .266$ & 2,75 & 17.830 .125 & $\$ 1.434 .124 .236$ & $\begin{array}{c}- \\
1,90 \% \\
\end{array}$ & $\begin{array}{c}- \\
3,55 \% \\
\end{array}$ & $\begin{array}{c}- \\
12,13 \% \\
\end{array}$ \\
\hline \multicolumn{2}{|c|}{ Toplam } & 192.004.486.042 & 78,31 & & & & & \\
\hline
\end{tabular}

Not: https://coinmarketcap.com internet sayfasındaki veriler kullanılarak oluşturulmuştur. Erişim Tarihi:08.05.2019.

Tablo 1'e göre beş kripto para \%78 gibi pazarın önemli bir bölümünü temsil etmektedir. Diğer kripto paralar ise piyasadaki ağırlıklarının düşük olması sebebiyle çalışma kapsamı dışında tutulmuştur. Piyasada en fazla işlem gören söz konusu beş kripto para için yapılacak analizlerin bütünü açıklamak için yeterli olacağ 1 varsayılmıştır.

Tablo 2: Veri Seti ve Tarih Aralığı

\begin{tabular}{|c|c|c|c|}
\hline Kripto Para & Sembol & Gözlem Aralı̆̆ & Gözlem Sayısı \\
\hline Bitcoin & BTC & $28.04 .2013-09.06 .2019$ & 2234 \\
\hline Ethereum & ETH & $07.08 .2015-09.06 .2019$ & 1403 \\
\hline XRP & XRP & $04.08 .2013-09.06 .2019$ & 2136 \\
\hline Litecoin & LTC & $28.04 .2013-09.06 .2019$ & 2234 \\
\hline Bitcoin Cash & BCH & $23.07 .2017-09.06 .2019$ & 687 \\
\hline
\end{tabular}

Çalışmaya pazar payı büyüklügüüne göre en fazla payı alan beş kripto alınmış ve gözlem sayısı ve aralıkları Tablo 2'de sunulmuştur. Tablo 2'ye göre piyasadaki en eski kripto paralar Bitcoin ve Litecoin'dir. Litecoin, Bitcoin ile aynı zamanda piyasaya girmesine rağmen pazar payı \%2,94'lerdedir.. En fazla pazar payına sahip para birimi ise \%55,71 ile Bitcoin olmuştur. Tablo 3’te söz konusu analize dahil edilen kripto paralara ilişkin betimleyici istatistikler verilmiştir. 
Tablo 3: Açıklayıcı Özet İstatistik

\begin{tabular}{|l|c|c|c|c|c|c|c|}
\hline Kripto Para & \multirow{2}{*}{$\mathrm{N}$} & Ort. & Std.Sapma & Max & Min & Çarpıklık & Basıklık \\
\hline Bitcoin & 2234 & 2500.61 & 3391.19 & 19497.40 & 68.43 & 1.816 & 6.309 \\
\hline Ethereum & 1403 & 205.11 & 259.73 & 1396.42 & 0.43 & 1.680 & 5.707 \\
\hline XRP & 2136 & 0.18 & 0.33 & 3.38 & 0.00 & 3.896 & 26.257 \\
\hline Litecoin & 2234 & 33.44 & 52.95 & 358.34 & 1.16 & 2.559 & 10.447 \\
\hline Bitcoin Cash & 687 & 722.39 & 614.16 & 3923.07 & 77.37 & 1.724 & 6.469 \\
\hline
\end{tabular}

Tablo 3'teki en çarpıcı nokta standart sapmaların büyük olmasıdır. Söz konusu beş kripto paranın yaklaşık ortalama değeri kadar bir standart sapmaya sahip olmaları söz konusu kripto paraların volatilitesinin ne kadar yüksek olduğunu kanıtlar niteliktedir. Günlük ve haftalık fiyat değişimlerinin \%50’lere kadar ulaşması bu şekilde açıklanabilir. Bitcoin Cash gibi piyasaya yeni giren bir paranın 77.37 \$ seviyesinden 3.923 \$'lı görmesinin veya aynı oranda düşüşünün sebebini bulmak zordur. Çünkü ulusal bir paranın fiyatını etkileyen faiz oranı, enflasyon, cari açık, kamu borcu, dış ticaret hadleri, istikrar, hükümet politikaları gibi birçok faktör var iken kripto paralar için bu kadar büyük fiyat değişimlerine yol açacak net bir faktörü belirlemek zordur.

\subsection{Analiz}

Kripto para piyasasının etkin bir piyasa olup olmadığını belirlemek için beş kripto paranın birim kök içerip içermediğinin yani durağan olup olmadığının belirlenmesi gerekmektedir. İlk olarak yapısal kırılmaları dikkate almayan birinci nesil birim kök testleri (ADF, PP) ile serilerin durağan olup olmadığına bakılmıştır. Sonra seri içinde yapısal kırılmaların olup olmadığına bakılarak var ise yapısal kırılmaları dikkate alan birim kök testleri (Zivot Andrews Birim Kök Testi, Clemente-MontanesReyes Birim Kök Testi) kullanılmıştır. Böylelikle birinci nesil birim kök nesil sonuçlarının doğruluğu teyit edilecektir.

Zaman serisinin durağan olmasından kast edilen ortalaması ve varyansının zaman içinde değişmemesi ve kovaryansının ise dönemler arasındaki gecikmeye bağlı olup zamana bağlı olmaması durumudur (Atik vd., 2015: 254). Zaman serileri durağan olmaması durumunda stokastik ya da deterministik trend içerecektir. Durağan bir zaman serisinin ortalaması, varyansı ve kovaryansı zamandan bağımsız olmakta, zaman içinde değişmemektedir. Böyle bir zaman serisi kendi ortalaması etrafinda sabit genişlikte salınımlar gösterecektir. Serinin bu özelliğine ortalamaya dönüş (mean reversion) denilmektedir. Durağan seriler literatürde zayıf durağan (weakly stationary), kovaryans durağan (covariance stationary) şeklinde farklı isimlerle de kullanılmaktadır. Durağanlılığı açıklamak için Yt'nin bir seri olduğu farz edildiğinde;

$$
\mathrm{E}(\mathrm{Yt})=\mu
$$

$$
\operatorname{Var}(\mathrm{Yt})=\gamma 0
$$


$\operatorname{Cov}(\mathrm{Yt}, \mathrm{Yt}+\mathrm{k})=\gamma \mathrm{k}$

Başlangıç noktasını t noktasından, $\mathrm{t}+\mathrm{k}$ 'ya getirdiğimizde eğer Yt serisi durağan ise $\mathrm{Yt}$, ve $\mathrm{Yt}+\mathrm{k}$ serilerinin ortalama, varyans ve kovaryanslarının aynı olması gerekmektedir. Ancak k, 0 ise

$\operatorname{Cov}(Y t, Y t+0)=\operatorname{Var}(Y t)=\sigma 2$ şeklinde olacaktır.

Zaman serisi durağan değil (durağan dışı- non stationary) ise serinin ortalamas1, varyansı veya her ikisi birden zamana bağlı olarak değişecektir. Seri durağan olmaması durumunda serinin davranışı diğer dönemler için genellenemeyecek ve geleceği tahmin etmek için kullanılamayacaktır (Yalta, 2011).

$\mathrm{Bu}$ yüzden serinin durağanlığını kontrol etmek için birinci nesil testlerinden Augmented Dickey Fuller (ADF) ve Phillips-Perron (PP) birim kök testleri seçilmiştir. ADF testi, hata terimlerinin farklı varyans ve seri korelasyon içerecek şekilde rassal ve homojen dağıldıkları varsayımı için kullanılmaktadır (Gujarati, 2006).

$$
\Delta Y_{t}=\beta_{1}+\beta_{2} \cdot t+\delta . Y_{t-1}+\alpha_{i} \cdot \sum_{i=1}^{m} \Delta Y_{t-i}+\varepsilon_{t}
$$

$\Delta \mathrm{Yt}=$ Durağanlığı test edilen serinin birinci farkını, $\mathrm{t}=$ Trend değişkenini, $\Delta \mathrm{Y}_{\mathrm{t}-\mathrm{i}}=$ Gecikmeli fark1, $\varepsilon_{\mathrm{t}}=$ Ortalaması 0 , ardışı bağımlılığı olmayan, varyansı değişmeyen hata terimidir. ADF birim kök testinde,

$\mathrm{H}_{0}=\alpha_{1}=0$

$\mathrm{H}_{1}=\alpha_{1}<0$

Şeklinde olup, H0'ın red edilmesi serinin durağan olup, birim kök içermediği anlamına gelmektedir. Tablo 4 ve Tablo 5'te ADF ve PP birim kök test sonuçları verilmiştir. 
Tablo 4: Kripto Paralara Ait ADF (Augmented Dickey-Fuller) Birim Kök Test Sonuçları

\begin{tabular}{|c|c|c|c|c|c|}
\hline \multirow{2}{*}{ S.Nu. } & \multirow{2}{*}{$\begin{array}{l}\text { Kripto } \\
\text { Paralar }\end{array}$} & \multicolumn{2}{|c|}{$\mathrm{I}_{0}$} & \multicolumn{2}{|c|}{$\mathrm{I}_{1}$} \\
\hline & & Sabit & Trend + Sabit & Sabit & Trend + Sabit \\
\hline \multirow{4}{*}{1} & \multirow{4}{*}{ Bitcoin } & $\begin{array}{r}-1.8753 \\
(0.344)\end{array}$ & $\begin{array}{c}-2.9787 \\
(0.138)\end{array}$ & $\begin{array}{l}-8.6876 \\
(0.000)\end{array}$ & $\begin{array}{r}-8.6924 \\
(0.000)\end{array}$ \\
\hline & & $-3.4331[\mathrm{a}]$ & $-3.9621[\mathrm{a}]$ & $-3.4331[\mathrm{a}]$ & $-3.9621[\mathrm{a}]$ \\
\hline & & $-2.8626[b]$ & $-3.4118[b]$ & $-2.8626[\mathrm{~b}]$ & $-3.4118[b]$ \\
\hline & & $-2.5674[\mathrm{c}]$ & $-3.1278[\mathrm{c}]$ & $-2.5674[\mathrm{c}]$ & $-3.1278[\mathrm{c}]$ \\
\hline \multirow{4}{*}{2} & \multirow{4}{*}{ Ethereum } & $\begin{array}{c}-2.3883 \\
(0.145)\end{array}$ & $\begin{array}{c}-2.6118 \\
(0.275)\end{array}$ & $\begin{array}{c}-5.7836 \\
(0.000)\end{array}$ & $\begin{array}{c}-5.7880 \\
(0.000)\end{array}$ \\
\hline & & $-3.4348[\mathrm{a}]$ & $-3.9646[\mathrm{a}]$ & $-3.4348[\mathrm{a}]$ & $-3.9646[a]$ \\
\hline & & $-2.8634[\mathrm{~b}]$ & $-3.4130[\mathrm{~b}]$ & $-2.8634[\mathrm{~b}]$ & $-3.4130[\mathrm{~b}]$ \\
\hline & & $-2.5678[\mathrm{c}]$ & $-3.1285[\mathrm{c}]$ & $-2.5678[\mathrm{c}]$ & $-3.1285[\mathrm{c}]$ \\
\hline \multirow{4}{*}{3} & \multirow{4}{*}{ XRP } & $\begin{array}{c}-3.7228 \\
(0.003)\end{array}$ & $\begin{array}{r}-4.6497 \\
(0.000)\end{array}$ & - & - \\
\hline & & $-3.4332[\mathrm{a}]$ & $-3.9623[\mathrm{a}]$ & - & - \\
\hline & & $-2.8627[\mathrm{~b}]$ & $-3.4119[\mathrm{~b}]$ & - & - \\
\hline & & $-2.5674[\mathrm{c}]$ & $-3.1278[\mathrm{c}]$ & - & - \\
\hline \multirow{4}{*}{4} & \multirow{4}{*}{ Litecoin } & $\begin{array}{c}-2.5355 \\
(0.107)\end{array}$ & $\begin{array}{c}-3.3516 \\
(0.058)\end{array}$ & $\begin{array}{c}-8.4228 \\
(0.000)\end{array}$ & $\begin{array}{c}-8.4272 \\
(0.000)\end{array}$ \\
\hline & & $-3.4331[\mathrm{a}]$ & $-3.9622[\mathrm{a}]$ & $-3.4331[\mathrm{a}]$ & $-3.9622[\mathrm{a}]$ \\
\hline & & $-2.8626[b]$ & $-3.4118[b]$ & $-2.8626[b]$ & $-3.4118[b]$ \\
\hline & & $-2.5674[\mathrm{c}]$ & $-3.1278[\mathrm{c}]$ & $-2.5674[\mathrm{c}]$ & $-3.1278[\mathrm{c}]$ \\
\hline \multirow{4}{*}{5} & \multirow{4}{*}{ Bitcoin Cash } & $\begin{array}{c}-2.1798 \\
(0.214)\end{array}$ & $\begin{array}{c}-2.7392 \\
(0.221)\end{array}$ & $\begin{array}{c}-21.7159 \\
(0.000)\end{array}$ & $\begin{array}{c}-21.7099 \\
(0.000)\end{array}$ \\
\hline & & $-3.4396[a]$ & $-3.9714[\mathrm{a}]$ & $-3.4396[\mathrm{a}]$ & $-3.9715[\mathrm{a}]$ \\
\hline & & $-2.8655[b]$ & $-3.4163[b]$ & $-2.8655[\mathrm{~b}]$ & $-3.4164[b]$ \\
\hline & & $-2.5689[\mathrm{c}]$ & $-3.1305[\mathrm{c}]$ & $-2.5689[\mathrm{c}]$ & $-3.1305[\mathrm{c}]$ \\
\hline
\end{tabular}

Not: ADF birim kök testi için uygun gecikme sayısı Schwarz Bilgi Kriterine göre belirlenmiştir. [a], [b] ve [c]*** sirasıyla 0.01, 0.05 ve 0.10 için Mac-Kinnon kritik değerlerini göstermektedir. Parantez içindeki değerler testlerin olasılık değerleridir. 
Tablo 5: Kripto Paralara Ait Phillips-Perron (PP) Birim Kök Test Sonuçları

\begin{tabular}{|c|c|c|c|c|c|}
\hline \multirow{2}{*}{ S.Nu. } & \multirow{2}{*}{$\begin{array}{l}\text { Kripto } \\
\text { Paralar }\end{array}$} & \multicolumn{2}{|c|}{$\mathrm{I}_{0}$} & \multicolumn{2}{|c|}{$\mathrm{I}_{1}$} \\
\hline & & Sabit & Trend + Sabit & Sabit & Trend + Sabit \\
\hline \multirow{4}{*}{1} & \multirow{4}{*}{ Bitcoin } & $\begin{array}{c}-1.479664 \\
(0.544)\end{array}$ & -2.438131 & $\begin{array}{r}-43.9357 \\
(0.000)\end{array}$ & $\begin{array}{c}-43.9274 \\
(0.000)\end{array}$ \\
\hline & & $-3.4330[\mathrm{a}]$ & $-3.9621[\mathrm{a}]$ & $-3.4330[\mathrm{a}]$ & $-3.9621[\mathrm{a}]$ \\
\hline & & $-2.8626[\mathrm{~b}]$ & $-3.4118[\mathrm{~b}]$ & $-2.8626[\mathrm{~b}]$ & $-3.4118[\mathrm{~b}]$ \\
\hline & & $-2.5673[\mathrm{c}]$ & $-3.1278[\mathrm{c}]$ & $-2.5673[\mathrm{c}]$ & $-3.1278[\mathrm{c}]$ \\
\hline \multirow{4}{*}{2} & \multirow{4}{*}{ Ethereum } & $\begin{array}{c}-1.7014 \\
(0.430)\end{array}$ & $\begin{array}{l}-1.7607 \\
(0.723)\end{array}$ & $\begin{array}{c}-35.71651 \\
(0.000)\end{array}$ & $\begin{array}{c}-35.7064 \\
(0.000)\end{array}$ \\
\hline & & $-3.4348[\mathrm{a}]$ & $-3.9646[\mathrm{a}]$ & $-3.4348[\mathrm{a}]$ & $-3.9646[a]$ \\
\hline & & $-2.8633[b]$ & $-3.4130[\mathrm{~b}]$ & $-2.8633[b]$ & $-3.4130[\mathrm{~b}]$ \\
\hline & & $-2.5678[\mathrm{c}]$ & $-3.1285[\mathrm{c}]$ & $-2.5678[\mathrm{c}]$ & $-3.1285[\mathrm{c}]$ \\
\hline \multirow{4}{*}{3} & \multirow{4}{*}{ XRP } & $\begin{array}{c}-3.579333 \\
(0.006)\end{array}$ & $\begin{array}{r}-4.3938 \\
(0.002)\end{array}$ & - & - \\
\hline & & $-3.4332[\mathrm{a}]$ & $-3.9623[\mathrm{a}]$ & - & - \\
\hline & & $-2.8626[b]$ & $-3.4119[\mathrm{~b}]$ & - & - \\
\hline & & $-2.5674[\mathrm{c}]$ & $-3.1278[\mathrm{c}]$ & - & - \\
\hline \multirow{4}{*}{4} & \multirow{4}{*}{ Litecoin } & $\begin{array}{l}-2.2718 \\
(0.181)\end{array}$ & $\begin{array}{r}-3.0208 \\
(0.126)\end{array}$ & $\begin{array}{c}-44.2576 \\
(0.000)\end{array}$ & $\begin{array}{c}-44.2488 \\
(0.000)\end{array}$ \\
\hline & & $-3.4330[a]$ & $-3.9621[\mathrm{a}]$ & $-3.4330[\mathrm{a}]$ & $-3.9621[\mathrm{a}]$ \\
\hline & & $-2.8626[b]$ & $-3.4118[\mathrm{~b}]$ & $-2.8626[b]$ & $-3.4118[b]$ \\
\hline & & $-2.5673[\mathrm{c}]$ & $-3.1278[\mathrm{c}]$ & $-2.5673[\mathrm{c}]$ & $-3.1278[\mathrm{c}]$ \\
\hline \multirow{4}{*}{5} & \multirow{4}{*}{$\begin{array}{l}\text { Bitcoin } \\
\text { Cash }\end{array}$} & $\begin{array}{l}-2.0343 \\
(0.272)\end{array}$ & $\begin{array}{l}-2.6021 \\
(0.279)\end{array}$ & $\begin{array}{c}-27.2361 \\
(0.000)\end{array}$ & $\begin{array}{c}-27.2252 \\
(0.000)\end{array}$ \\
\hline & & $-3.4396[\mathrm{a}]$ & $-3.9714[\mathrm{a}]$ & $-3.4396[a]$ & $-3.9715[\mathrm{a}]$ \\
\hline & & $-2.8655[b]$ & $-3.4163[b]$ & $-2.8655[\mathrm{~b}]$ & $-3.4163[\mathrm{~b}]$ \\
\hline & & $-2.5689[\mathrm{c}]$ & $-3.1305[\mathrm{c}]$ & $-2.5689[\mathrm{c}]$ & $-3.1305[\mathrm{c}]$ \\
\hline
\end{tabular}

Not: PP birim kök testinde tahmin metodu Bartlett Kernel kullanılmışıır. [a], [b] ve [c]*** sırasıyla $0.01,0.05$ ve 0.10 için Mac-Kinnon kritik değerlerini göstermektedir. Parantez içindeki değerler testlerin olasılık değerleridir.

ADF ve PP birim kök test sonuçlarına göre XRP kripto para birimi dişındaki bütün para birimlerinin birim kök içerdiği yani düzeyde durağan olmadıkları görülmektedir. Ancak yapısal kırılmanın varlığı durumunda standart birim kök 
testlerinin, birim kök hipotezinin kabulü yönünde sonuçlar vermesi sebebiyle yapısal kırılmanın olup olmadığının test edilmesi gerekmektedir. Öncelikle her bir kripto para biriminin Şekil 1'deki grafikleri incelenmiştir.

\section{Şekil 1: Kripto Paraların Fiyat Hareketleri}

bch
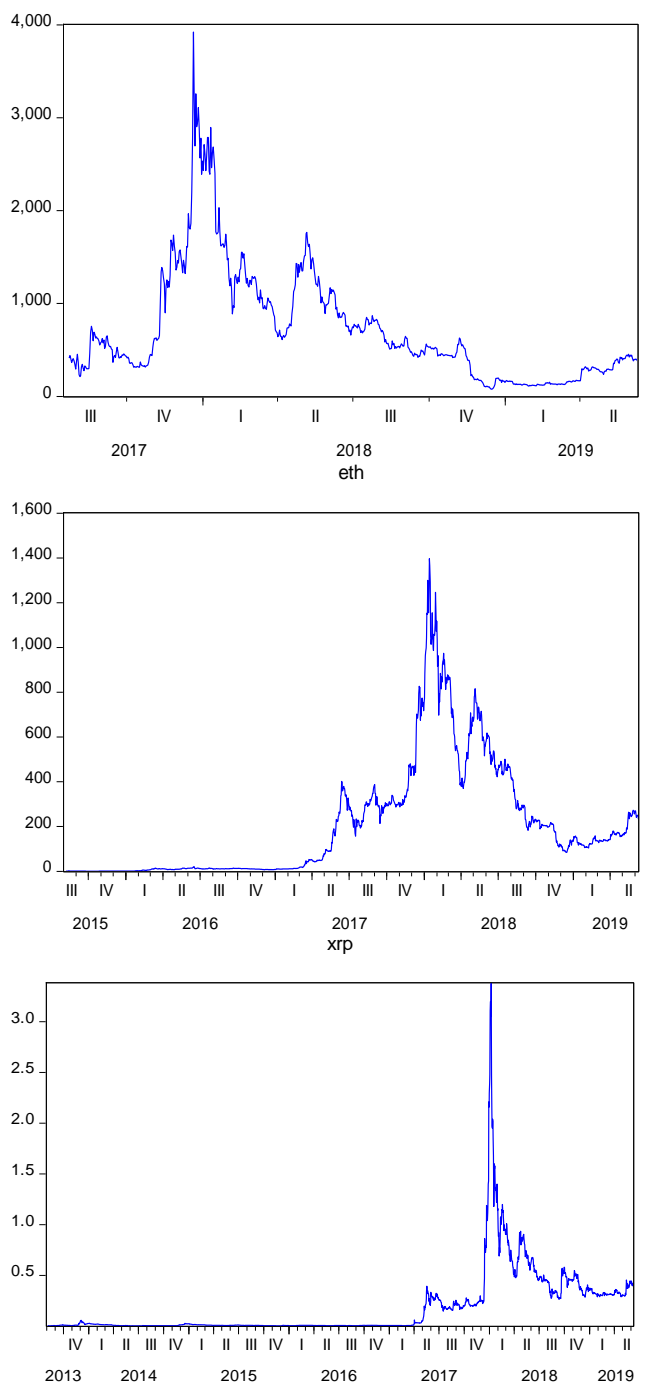

btc

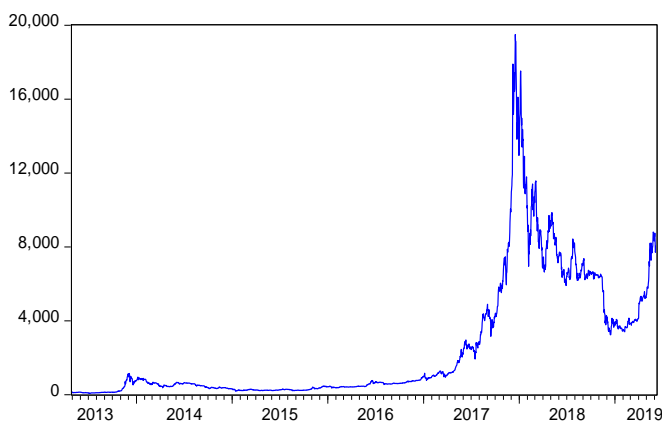

Itc

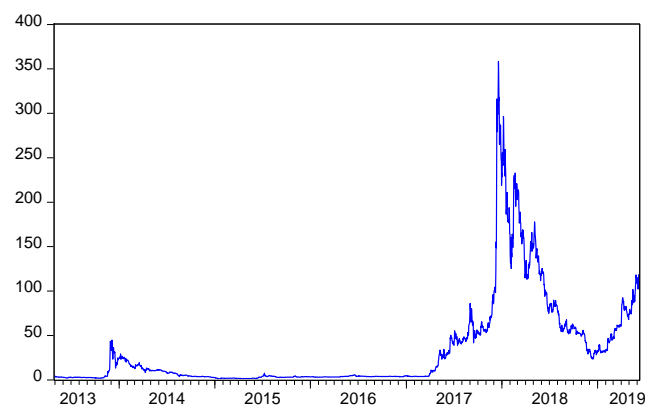

Şekil 1'e göre kripto paraların fiyat hareketlerinde yapısal kırılmaların olabileceği görülmektedir. Yapısal kırılmalar kriz, şok gibi durağan dışı bir olay sonrası 
oluşabilmektedir. Olası bir yapısal kırılmanın varlığının göz ardı edilmesi, birim kök testlerinin sonuçlarını etkileyerek, geleneksel birinci nesil testlerin $\mathrm{H}_{0}$ hipotezini red edilmemesine sebep olabilecektir (Çelik, 2016:659-660). Bu yüzden öncelikle tek kırılmayı dikkate alan Zivot-Andrews Birim Kök Testi yapılmış ve sonuçları Tablo 6'da sunulmuştur.

\section{Tablo 6: Zivot-Andrews Birim Kök Test Sonuçları}

\begin{tabular}{|c|c|c|c|c|c|c|c|}
\hline \multirow{2}{*}{ Değişkenler } & \multirow{2}{*}{ Model } & \multirow{2}{*}{ Kırılma Dönemi } & \multicolumn{3}{|c|}{ Kritik Değerler } & \multirow{2}{*}{ Min. $t$ İstatistiği } & \multirow{2}{*}{$\mathrm{k}$} \\
\hline & & & $1 \%$ & $5 \%$ & $10 \%$ & & \\
\hline \multirow{3}{*}{ Bitcoin } & Model A & 17-Jul-17 & -5.34 & -4.8 & -4.58 & -3.724 & 6 \\
\hline & Model B & 19-Aug-15 & -4.93 & -4.42 & -4.11 & -2.613 & 6 \\
\hline & Model C & $15-$ Sep-17 & -5.57 & -5.08 & -4.82 & -4.743 & 6 \\
\hline \multirow{3}{*}{ Bitcoin Cash } & Model A & 9-Nov-17 & -5.34 & -4.8 & -4.58 & -3.649 & 4 \\
\hline & Model B & 24-Nov-17 & -4.93 & -4.42 & -4.11 & -3.235 & 4 \\
\hline & Model C & 15-Jan-18 & -5.57 & -5.08 & -4.82 & -4.556 & 4 \\
\hline \multirow{3}{*}{ Ethereum } & Model A & 18-Jul-18 & -5.34 & -4.8 & -4.58 & -3.517 & 6 \\
\hline & Model B & 5-Jan-18 & -4.93 & -4.42 & -4.11 & -3.271 & 6 \\
\hline & Model C & 18-Nov-17 & -5.57 & -5.08 & -4.82 & -4.754 & 6 \\
\hline \multirow{3}{*}{ XRP } & Model A & 8-Dec-17 & -5.34 & -4.8 & -4.58 & -5.912 & 6 \\
\hline & Model B & 2-Jan-16 & -4.93 & -4.42 & -4.11 & -5.052 & 6 \\
\hline & Model C & 12-Dec-17 & -5.57 & -5.08 & -4.82 & -8.587 & 6 \\
\hline \multirow{3}{*}{ Litecoin } & Model A & 15-Sep-17 & -5.34 & -4.8 & -4.58 & -4.469 & 6 \\
\hline & Model B & 20 -Nov-15 & -4.93 & -4.42 & -4.11 & -3.751 & 6 \\
\hline & Model C & 13-Nov-17 & -5.57 & -5.08 & -4.82 & -5.955 & 6 \\
\hline
\end{tabular}

Not: Model A, Model B ve Model C sirasiyla Sabitte, Trendde, Hem Sabitte Hem Trendde kırılmanın olduğu modelleri temsil etmektedir. $\mathrm{k}$ lag sayısını ve * simgesi $\% 5$ anlamlılık düzeyini ifade etmektedir.

Tablo 6'daki Zivot-Andrews Birim Kök Testi sonuçlarına göre XRP kripto para birimi dışındaki kripto paraların tamamının durağan olmadıkları görülmektedir. Ancak yapısal kırılmanın birden fazla olması durumunda Zivot-Andrews Birim Kök Test sonuçları yanlış olabilecektir. Bunu test etmek için iki yapısal kırılmalı birim kök testi olan Clemente-Montanes-Reyes uygulanmış ancak kırılmanın tek olduğu görülmüştür.

XRP fiyat serisinin durağan çıkmasının sebebi diğer kripto paralardan farklı yönlerinin bulunmasıdır. XRP'in diğer kripto paralardan en önemli farkı merkezi olmayan bir teknolojinin merkezi versiyonu olmasıdır. Bitcoin, Ethereum ve diğer kripto paralar milyonlarca küresel madenciyle desteklendiği için hiç kimsenin ağlar üzerinde gerçek kontrolü bulunmamaktadır. XRP ise onu başlatan şirket olan Ripple Labs ve diğer birkaç finans kurumu tarafindan kontrol edilmesi tek merkezden yönetilen bir kuruluş haline getirmektedir. Ayrıca XRP'nin bir madencilik süreci de yoktur. Bu yüzden Ripple diğer kripto para birimlerinden farklıdır. 


\section{Sonuç}

Çalışmaya dahil edilen beş kripto para üzerinde yapılan analizler sonucunda kripto paraların düzeyde durağan olmadıkları yani birim kök içerdikleri tespit edilmiştir. Bu durum kripto paraların ortalamasının, varyansının veya her ikisinin de zamana bağlı olarak değişebileceği anlamına gelmektedir. Böyle bir durum rassal yürüyüş teorisiyle de uyum olarak kripto paraların geçmişteki fiyat hareketlerini kullanarak, geleceğe ilişkin bir fiyat tahmininin yapılmasının mümkün olabileceği anlamına gelmektedir. Etkin piyasa hipotezine göre kripto para serilerinin düzeyde durağan olmaması durumunda geçmişteki fiyat hareketlerini kullanarak normalin üstünde bir getiri elde edilmesi mümkün olmaktadır.

Kripto paraların getiri oranlarındaki değişimler göz önüne alındığında risk faktörünün yüksek olması bir yatırım aracı değil bir şans oyunu gibi algılanmalarına sebep olabilmektedir. Beş farklı kripto para biriminin, incelenen zaman dilimlerinde fiyat oynaklıklarının aşırı derecede yüksek olması ve dolayısıyla aşııı riskli olması, arztalep uyumsuzluğu, parasal otorite yokluğu gibi nedenlerden sonra beklenen bir sonuçtur. Yatırım aracına etki eden faktörler itibari paralar için belirli iken kripto paralarda net değildir. Kripto paraların kısa zaman diliminde değerinde oluşan yükseliş ve düşüşlerin sebeplerini açıklamak zordur. Bu durum neden yükseldiğinin veya neden düştüğünün belirli olmaması sebebiyle yatırım aracı olarak görülebilme fonksiyonunu sorgulatmaktadır.

Çalışmanın bulguları literatürle de uyumludur. Parlaktuna ve Güngül (2020) kripto paraların, paranın değer saklama ve tasarruf yani servet biriktirme aracı olarak görülme fonksiyonlarını yerini getirmediğini bu yüzden para olarak görülemeyeceğini, Kesebir ve Günceler (2019) kripto paralardaki ani fiyat hareketlerinin kripto paraya olan güven duygusunu etkilediğini ve Nishibe (2020)'de kripto paranın istikrar kriterlerini sağlayamadığı vurgulamışlardır. Bu açıdan incelendiğinde de çalışmada elde edilen bulgular ile örtüşmektedir.

Paranın değişim aracı, tasarruf aracı ve hesap birimi olmak üzere üç temel fonksiyonu vardır. Kripto para birimleri genel olarak bir değişim aracı olarak kullanılabileceği değerlendirilmekle birlikte, bu para birimlerine olan değişken talep, esnek olmayan arz ve arzın kontrolünü sağlayabilecek bir otoritenin olmaması sebebiyle tasarruf aracı ve hesap birimi olma fonksiyonlarını karşılayamayacağı, bu yüzden kripto paraların mevcut durumda para olarak kabul edilmesinin erken olabileceği değerlendirilmektedir. Ayrıca birçok ülkede kripto paralarla ilgili yasal düzenlemelerin halen olmaması bu görüşü doğrular niteliktedir. Kripto paraların ortaya çıkış hızları değerlendirildiğinde kısa zaman içinde piyasada geldikleri noktalara bakılarak gelecekte piyasa içinde para, varlık, stok vb. diğer herhangi bir şekilde olabilecekleri görülmektedir. 


\section{Kaynakça} Crypto Currencies As Money

Avunduk, H. ve Aşan, H. (2018). "Blok Zinciri (Blockchain) Teknolojisi ve İşletme Uygulamaları: Genel Bir Değerlendirme”, Dokuz Eylül Üniversitesi İktisadi ve İdari Bilimler Fakültesi Dergisi, 33(1), 374.

Atik, M., Köse Y., Yılmaz B., Sağlam F. (2015). “Kripto Para: Bitcoin ve Döviz Kurlar1 Üzerine Etkileri", Bartın Üniversitesi İktisadi ve İdari Bilimler Fakültesi Dergisi, 6 (11), 247-262.

Berk, N. (2011). Finansal Yönetim, 11. Baskı Türkmen Kitabevi.

Butler, S. (2019). Criminal use of cryptocurrencies: a great new threat or is cash still king?. Journal of Cyber Policy, 4(3), 326-345.

Coinmarketcap https://coinmarketcap.com/, Erişim Tarihi 08.05.2019.

Çarkacıoğlu, A. (2016). Kripto-Para Bitcoin, Sermaye Piyasası Kurulu Araştırma Dairesi Araştırma Raporu, 15-17.

Çelik, N. (2016). Yapısal Kırılmalar Altında Kamu-Özel Kesim Yatırım Harcamaları İlişkisi, Yönetim ve Ekonomi, 23(3), 659-660.

Demirdöğen, Y.(2019). Fintek Ekosistemi İçin Gerekli Düzenlemeler. Süleyman Demirel Üniversitesi Vizyoner Dergisi, 10 (24), 311-312.

Doğan, Ş. (2020). Dijital Çağda Paranın Dönüşümü: Kripto Para Birimleri ve Blok Zinciri (Blockchain) Teknolojisi: Üniversite Öğrencilerine Yönelik Bir Araştırma. Anemon Muş Alparslan Üniversitesi Sosyal Bilimler Dergisi, 8(3), 859-870.

Duque, J. (2020). State involvement in Cryptocurrencies. A potential world money?. The Japanese Political Economy, 46(1), 65-82.

Fama, E.F. (1965). The Behavior of Stock Market Prices. The Journal of Business, 38 (1), 34-105.

Fama, E.F. (1995). Random Walks in Stock Market Prices, Financial Analysts Journal, 51(1), 75-80.

Fantacci, L., (2019). Cryptocurrencies and the Denationalization of Money. International Journal of Political Economy, 48(2), 105-126.

Grobys, K.,Sapkota, N. (2019). Predicting cryptocurrency defaults, Applied Economics, 52(46), 5060-5076.

Gujarati, D.N. (2006). Temel Ekonometri, (Çev. Ü. Şenesen ve G.G. Şenesen), Literatür Yayıncılık, İstanbul. 

Üzerine Ampirik Bir Uygulama 17.

Kaplanhan, F.(2018). Kripto Paranın Türk Mevzuatı Açısından Değerlendirilmesi: Bitcoin Örneği, Vergi Mevzuatı ve Maliye Teorisi, Sayı 353 , 106.

Kesebir, M. ve Günceler, B.(2019). Kripto Para Birimlerinin Parlak Geleceği. Iğdır Üniversitesi Sosyal Bilimler Dergisi, Sayı 17, 607.

Lee, D., Chuen K., Guo, L. and Wang, Y. (2018). Cryptocurrency: A New Investment Opportunity?. The Journal of Alternative Investments Winter 2018, 20 (3) 1640.

Lemieux, V.L. (2016). Trusting records: is Blockchain technology the answer?. Records Management Journal, 26(2), 110-113.

Malherbe, L., Montalban, M., Bédu N., Granier, C., (2019). Cryptocurrencies and Blockchain: Opportunities and Limits of a New Monetary Regime. International Journal of Political Economy, 48(2), 127-152

Mishkin, F.S. (2016). The Economics of Money, Banking, and Financial Markets Eleventh Edition Global Edition, Columbia University.

Nishibe, M., (2020). Good money drives out bad: Introduction to the featured section on The evolution of diverse e-money: Digital-community currencies and cryptocurrencies, The Japanese Political Economy, 46(1), 1-16.

Parlaktuna, İ. ve Güngül, M. (2020), Bitcoin'nin Tanımlanma Sorunu, Muhasebe ve Finansman Dergisi, Say1 86, 25-38.

Pirinççi, A.E.(2018). Yeni Dünya Düzeninde Sanal Para Bitcoin'in Değerlendirilmesi. International Journal of Economics Politics Humanities and Social Sciences, 1 (1), 45-51.

Şenbayram, E.A. (2019). Paranın Geldiği Uç Nokta: Bitcoin. Harran Üniversitesi İIBF Dergisi, 3 (4), 89-90.

Yalta, T. (2011). Zaman Serileri Ekonometrisine Giriş: Durağanlık ve Durağan Dışılık. TÜBA Ulusal Açı Ders Malzemeleri Konsorsiyumu, http://www.acikders.org.tr, Erişim Tarihi:14.06.2019).

Yıldırım, M. (2019). Blok Zincir Teknolojisi, Kripto Paralar ve Ülkelerin Kripto Paralara Yaklaşımları. Bartın Üniversitesi İktisadi ve İdari Bilimler Fakültesi Dergisi, 10 (20), 269. 